ARTICLE

https://doi.org/10.1038/s41467-018-07936-x

\title{
Emergence of a floral colour polymorphism by pollinator-mediated overdominance
}

\author{
Roman T. Kellenberger ${ }^{1,6}$, Kelsey J.R.P. Byers ${ }^{1,7}$, Rita M. De Brito Francisco ${ }^{2}$, Yannick M. Staedler ${ }^{3}$,
} Amy M. LaFountain ${ }^{4}$, Jürg Schönenberger ${ }^{3}$, Florian P. Schiestl ${ }^{1} \&$ Philipp M. Schlüter $^{1,5}$

Maintenance of polymorphism by overdominance (heterozygote advantage) is a fundamental concept in evolutionary biology. In most examples known in nature, overdominance is a result of homozygotes suffering from deleterious effects. Here we show that overdominance maintains a non-deleterious polymorphism with black, red and white floral morphs in the Alpine orchid Gymnadenia rhellicani. Phenotypic, metabolomic and transcriptomic analyses reveal that the morphs differ solely in cyanidin pigments, which are linked to differential expression of an anthocyanidin synthase (ANS) gene. This expression difference is caused by a premature stop codon in an ANS-regulating $R 2 R 3-M Y B$ transcription factor, which is heterozygous in the red colour morph. Furthermore, field observations show that bee and fly pollinators have opposite colour preferences; this results in higher fitness (seed set) of the heterozygous morph without deleterious effects in either homozygous morph. Together, these findings demonstrate that genuine overdominance exists in nature.

\footnotetext{
${ }^{1}$ Department of Systematic and Evolutionary Botany, University of Zurich, Zollikerstrasse 107, 8008 Zurich, Switzerland. ${ }^{2}$ Department of Plant and Microbial Biology, University of Zurich, Zollikerstrasse 107, 8008 Zurich, Switzerland. ${ }^{3}$ Department of Botany and Biodiversity Research, University of Vienna, Rennweg 14, 1030 Vienna, Austria. ${ }^{4}$ Department of Ecology and Evolutionary Biology, University of Connecticut, 75 North Eagleville Road, Storrs, CT 06269-3043, USA. ${ }^{5}$ Institute of Botany, University of Hohenheim, Garbenstraße 30, 70599 Stuttgart, Germany. ${ }^{6}$ Present address: Department of Plant Sciences, University of Cambridge, Downing Street, Cambridge CB2 3EA, UK. ${ }^{7}$ Present address: Department of Zoology, University of Cambridge, Downing Street, Cambridge CB2 3EJ, UK. Correspondence and requests for materials should be addressed to R.T.K. (email: rk615@cam.ac.uk) or to P.M.Süt. (email: philipp.schlueter@uni-hohenheim.de)
} 
$\mathrm{O}$ verdominance is defined as a fitness advantage of individuals based on heterozygosity at a single locus ${ }^{1}$. Historically, overdominance was considered an important mechanism maintaining polymorphism in natural populations, as it provides a simple explanation for the retention of multiple alleles in a population ${ }^{2,3}$. Although a range of putatively overdominant cases have been identified, very few are documented well enough to (1) establish a clear connection between genotype, phenotype and the selective force, and (2) exclude any influence of other genetic loci or other selection pressures on the examined phenotypic trait ${ }^{4,5}$. The well-understood examples are usually associated with intense, short-term selective pressures such as host-pathogen interactions ${ }^{6-8}$ or artificial selection ${ }^{4,9-15}$. In these cases, homozygosity of the derived allele generally has a detrimental effect on fitness, and cessation of selection would revert the fitness advantage of the heterozygote. Overdominance is thus often seen as a rather short-lived phenomenon, and its perceived significance in the maintenance of polymorphism has somewhat diminished in favour of other modes of selection ${ }^{16,17}$.

Polymorphism of visual traits such as colour has been studied for over a century, as it is easily accessible and can provide insights into fundamental evolutionary processes ${ }^{18}$. In plants, polymorphism of floral display traits is often highly fitness relevant due to their impact on the interactions of a plant with pollinators ${ }^{19,20}$. Most cases of floral polymorphism have been associated with antagonistic pleiotropy ${ }^{21-24}$, negative frequency dependence ${ }^{25,26}$ or spatiotemporal heterogeneity ${ }^{27-29}$. To our knowledge, the action of heterozygote advantage has been proposed in the colour-polymorphic annuals Cosmos bipinnatus ${ }^{30}$, Ipomoea purpurea ${ }^{31}$ and Sisyrinchium sp. ${ }^{32}$ However, selection on the Cosmos colour morphs may not be strictly overdominant as the morphs also differ in number and size of flowers; ${ }^{30}$ likewise, pollinator-mediated selection in the other two species seems to be influenced by other factors (pleiotropic effects of the colour locus in Ipomoea ${ }^{33,34}$ and reproductive interference in Sisyrinchium $^{35}$ ).

A yet unexplored floral colour polymorphism exists in a population of the Alpine orchid Gymnadenia (syn. Nigritella) rhellicani located on the Alpine plateau Puflatsch (Seiser Alm) in Northern Italy (Supplementary Table 1). Unlike in other locations, where the single inflorescences of G. rhellicani bear uniformly 'black' flowers, this population is strikingly polymorphic with $62 \%$ (wild type) 'black', 28\% 'red' and $10 \%$ 'white' individuals (census 2015, Fig. 1a). Within the population, there is no difference in the spatial distribution between morphs, which often grow in close proximity $(5 \mathrm{~cm})$ to each other (Supplementary Fig. 1), and morphs do not switch colour throughout their perennial life cycle. Variation in floral a
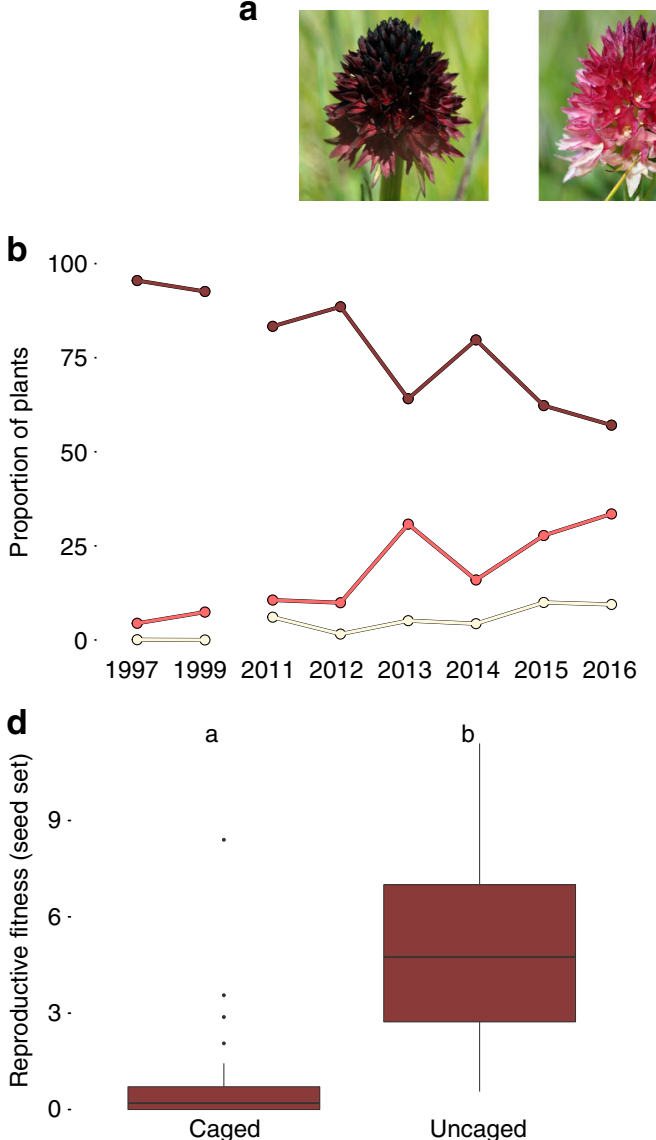

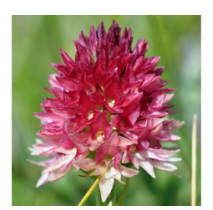

C
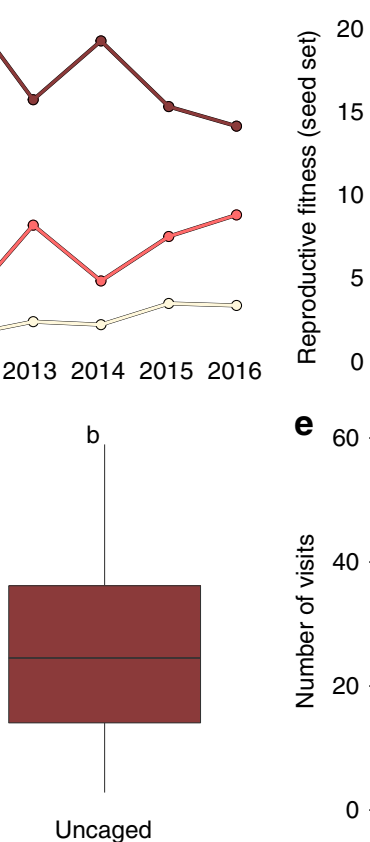

e 60

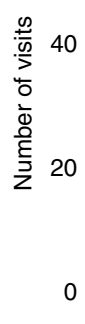

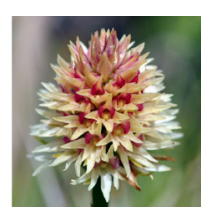
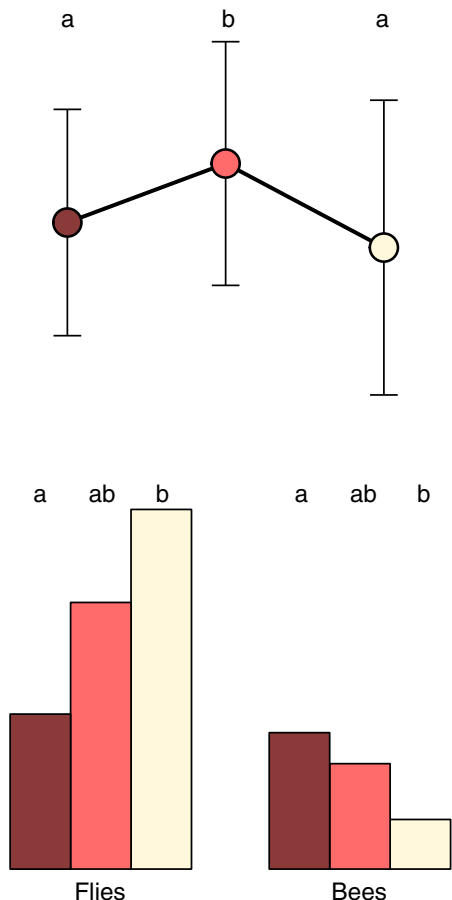

Fig. 1 Ecological evidence for overdominance in Gymnadenia rhellicani. a Three G. rhellicani floral colour morphs are growing intermixedly at Puflatsch. $\mathbf{b}$ The fraction of red and white morphs is increasing at Puflatsch, suggesting a fitness advantage of the white, red or both morphs. c Red, intermediate plants have the highest reproductive fitness (ANOVA $(n=173), F(4,168)=8.935, P=1.446 \times 10^{-6}$ and Tukey's HSD post hoc test $t_{\text {Black-Red }}=3.334, P_{\text {Black-Red }}=$ $\left.0.003, t_{\text {Black-White }}=-1.168, P_{\text {Black-White }}=0.467, t_{\text {Red-White }}=-3.250, P_{\text {Red-White }}=0.004\right)$; bars denote \pm 1 standard deviation). $\mathbf{d}$ Shielding plants (ungrazed Ofenpass site) from pollinators yielded low seed set, indicating pollinator-dependent reproduction (two-sided $t$ test $(n=42), t(34.818)=-4.939, P=$ $1.955 \times 10^{-5}$, the outlier value was caused by an accidentally trapped grasshopper leaving a hole in the net); centre lines denote medians, bounds of boxes denote first and third quartiles, whiskers denote $1.5 \times$ interquartile ranges. e Time-lapse recordings (2017), showing bee preference for dark and fly preference for bright plants, maximising seed set in the red morph ( $\chi^{2}$ test, Supplementary Fig. 1) 
a
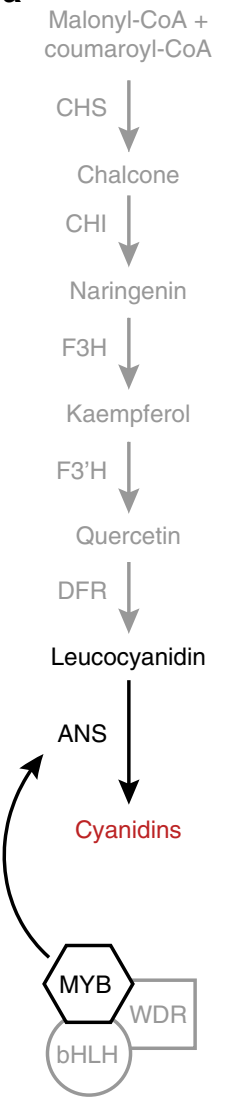

d

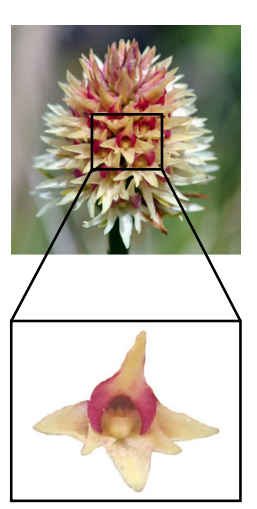

b

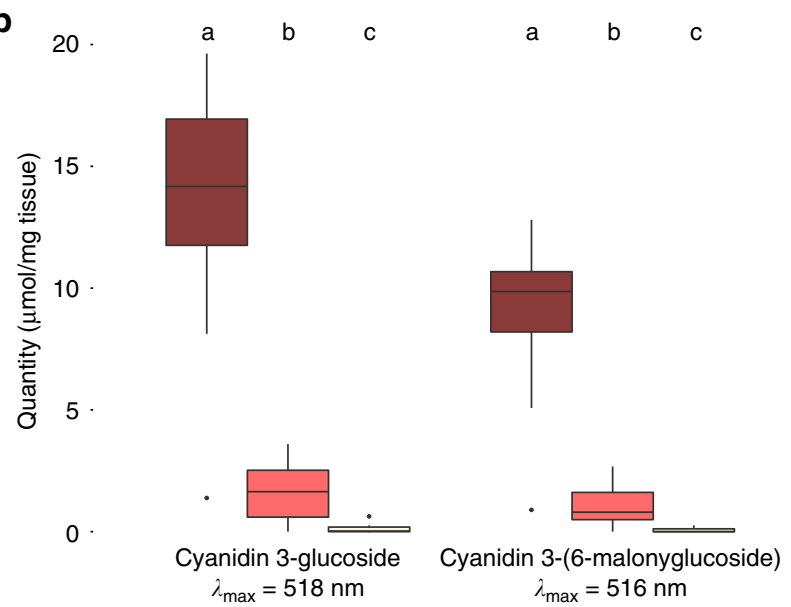

C

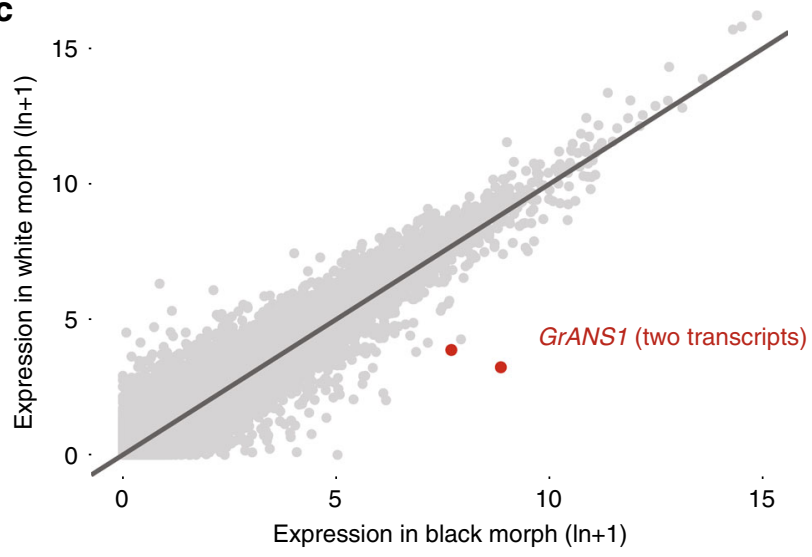

e 12.5 .

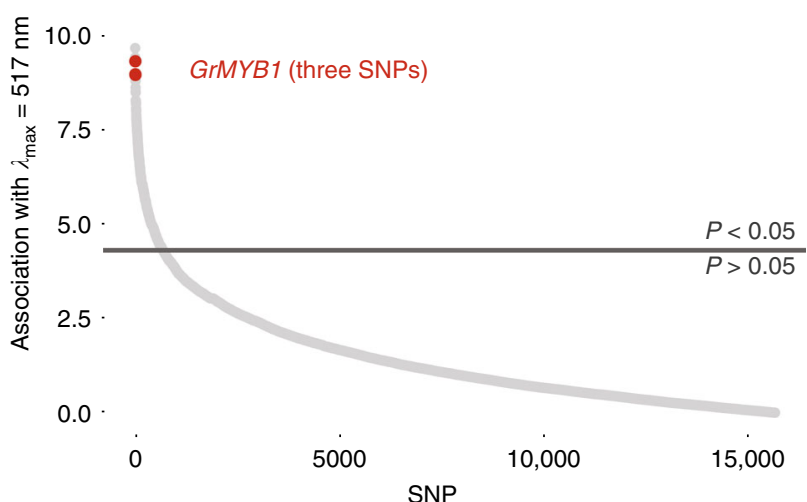

Fig. 2 Molecular developmental basis of the colour polymorphism. a Simplified diagram of the cyanidin branch of the anthocyanin pathway (see Supplementary Fig. 5), showing ANS and its typical regulation by MYB-bHLH-WDR transcription factor complexes. $\mathbf{b}$ Concentrations of the two main anthocyanin pigments found in G. rhellicani flowers (ANOVA; see Supplementary Fig. 4, Supplementary Table 6); centre lines denote medians, bounds of boxes denote first and third quartiles, whiskers denote $1.5 \times$ interquartile ranges. c Two of the 13 transcripts significantly differentially expressed between black and white plants map to GrANS1 (Supplementary Table 7). d Close-up of a 'white' flower; lateral labellum lobes still contain red pigment, suggesting a mutation in a regulator of spatial anthocyanin expression. e Transcriptome-wide association between SNPs and approximate cyanidin content (spectral reflectance): three top-10 SNPs occur in GrMYB1 (Supplementary Table 8)

coloration is thus likely genetically determined rather than a result of, for example, soil chemistry. To our knowledge, this population cannot be older than ca. 2000 years, when forests on Puflatsch were cleared; ${ }^{36}$ the first notion of the colour polymorphism is from $1906^{37}$, with a photographic record starting in $1971^{38}$. Moreover, frequency estimations conducted between 1997 and 2016 indicate an increase in relative abundance of the red and white colour morphs from total $<5 \%$ to $>40 \%$ (Fig. 1b, 1997-2014 data courtesy of Richard Lorenz). Although assessing evolutionary change from Hardy-Weinberg proportions in Gymnadenia populations is hampered by their pronounced age structure (cohorts of longlived, periodically dormant individuals $)^{39}$, the change in morph frequencies suggests the current action of strong 
selection pressure favouring the white, the intermediate or both alternate morphs in this system.

Here we use an eco-evo-devo approach to identify the genetic mechanism, the developmental basis and the evolutionary implications of the floral colour polymorphism in G. rhellicani. Taken together, our results suggest that this polymorphism has emerged by pollinator-mediated overdominance: the red colour morph is heterozygous for a single-nucleotide polymorphism (SNP), which introduces a premature stop codon in an $R 2 R 3$ $M Y B$ transcription factor. This leads to reduced expression of an anthocyanidin synthase (ANS) gene, resulting in a reduction of red cyanidin pigment in flower tissue, apparently without affecting other phenotypic traits. The two main pollinator groups of this population, bees and flies, show opposite colour preferences and both visit the red colour morph in relatively high numbers. As a consequence, the red colour morph has the highest seed set and increases in abundance. Overdominance in G. rhellicani thus appears entirely based on colour, and unlike in most other overdominant systems in natural populations, the mutation does not seem to cause any deleterious effects in either of the homozygotes.

\section{Results}

Evolutionary implications of the colour polymorphism. To assess the selective forces maintaining the floral colour polymorphism in G. rhellicani, we first quantified both inflorescence survival (fraction of inflorescences eaten by insects and livestock as well as reappearance of inflorescences in the next season) and reproductive fitness (number of fruits $\times$ percentage of viable seeds) of 281 plants (Supplementary Table 2). While there was no difference in inflorescence survival between colour morphs (Supplementary Fig. 2a), red plants had a significantly higher seed set than either of the extreme colour morphs (Fig. 1c). This pattern could mainly be attributed to variation in the number of fruits (Supplementary Fig. 2b and c), which in orchids develop only after successful pollination ${ }^{40}$, supporting the hypothesis of pollinator-mediated heterozygote advantage. Flow cytometry of collected pollinia identified all colour morphs as diploid (Supplementary Fig. 2d), and shielding plants with glass fibre mesh showed that pollinators are indeed required for seed set (Fig. 1d). This rules out apomictic or autogamous reproduction as known from polyploid Gymnadenia species $^{41}$.

Gymnadenia rhellicani is a nectar-producing plant visited by $>60$ different insect species from various orders ${ }^{42,43}$, and observations at Puflatsch have shown that pollination takes place during daytime with bees and flies as main carriers of pollinia (Supplementary Table 3). To test for differences in pollinator visitation, we (1) caught and identified insects on inflorescences in 2015, and placed ten cameras in front of (2) in situ pairs of black and red plants for four consecutive days in 2016, and (3) triplets of freshly cut inflorescences (one per colour morph) for 3 days in 2017, taking pictures every $60 \mathrm{~s}$ (2016: 25,007 frames; 2017: 14,419 frames). In 2016, we counted 160 landings of insects ( $18 \%$ bees, $81 \%$ flies and $1 \%$ other) and in 2017, we recorded 197 landings ( $24 \%$ bees, $64 \%$ flies and $12 \%$ other). While bees visit more dark than bright colour morphs, flies on the contrary visit more bright than dark colour morphs (Fig. 1e, Supplementary Fig. 2e, Supplementary Table 3). Although bees are less common, a limited survey in the population suggests that they are likely more efficient pollinators than flies ( 2 of 6 bees $=33 \%$ vs. 3 of 29 flies $=10 \%$ carried pollinia). Different preferences by bees and flies thus seem to exert opposite directional selection pressures on flower colour. The red, intermediate colour morph thereby attracts both pollinators in relatively high number, providing an explanation for the observed fitness advantage. Mapping of spectral reflectance data $(\lambda=300-700 \mathrm{~nm})$ of flowers (Supplementary Fig. $2 \mathrm{f}$ ) in the fly ${ }^{44,45}$ and bee ${ }^{46}$ visual spaces further suggested that both pollinator groups distinguish the colour morphs primarily based on luminance (Supplementary Fig. $2 \mathrm{~g}$ and $h$ ).

Phenotypic basis for pollinator choice. Considering these findings, bees and flies could either distinguish colour morphs by flower coloration intensity only or could rely on other phenotypic traits that correlate with colour. We therefore quantified a series of other potentially pollinator-relevant traits including plant height, flower number and inflorescence temperature in the morning and at noon, and also performed micro-computed tomography $(\mu \mathrm{CT})$ of flowers to assess three-dimensional $(3 \mathrm{D})$ floral morphology. Our analyses showed that the three colour morphs do not differ in any of these traits (Supplementary Fig. 3a-d). We also collected and analysed floral volatiles by headspace sorption and gas chromatography mass-selective detection (GC-MSD) and assessed the composition of the floral volatile bouquet ${ }^{47}$. Neither the whole volatile bouquet nor the emission of individual scent compounds were different between the colour morphs (with the exception of one minor compound, Supplementary Figs. 3e and 4, Supplementary Table 4). A comparison of temporal volatile emission between 10:00, 15:30 and 21:00 further showed that all colour morphs reduce volatile emission after sunset (Supplementary Fig. 3f). Gymnadenia rhellicani thus does not use floral volatiles to attract crepuscular or nocturnal pollinators. Altogether, these results suggest that the underlying mutation(s) only affect(s) flower coloration rather than acting in a pleiotropic fashion on multiple traits. This further strengthens the argument that flower colour may be under overdominant selection.

Developmental basis of the colour polymorphism. To characterise the molecular basis of this polymorphism, we combined the phenotypic measurements with metabolomic and transcriptomic data from the same individuals by extracting anthocyanin and carotenoid pigments as well as RNA from the same pool of four open flowers per individual. Quantification of anthocyanins and their colourless precursors with ultra-highperformance liquid chromatography (UHPLC-MS/MS) identified cyanidin-3-glucoside and a derivative, (putatively) cyanidin-3-(6malonylglucoside), as dominant pigments in the flowers. Another derivative, peonidin-3-glucoside, was also present to a lesser degree. The abundance of the two main cyanidin compounds is more than 7.5-fold lower in red, and more than 30-fold lower in white plants than in the black morph (Fig. 2b, Supplementary Fig. 5, Supplementary Tables 5 and 6). In contrast, HPLC quantification of carotenoids showed that the flowers mainly contain $\beta$-carotene and lutein with no difference in concentration between the three morphs (Supplementary Fig. 6a). Next, we performed messenger RNA-sequencing (mRNA-seq) of one plant per colour morph, three other wild-type black G. rhellicani plants from other populations, and four individuals of three closely related Gymnadenia species (Supplementary Table 2). We de novo assembled the Illumina HiSeq 2500 reads into a combined reference transcriptome, yielding a total of 836,101 contigs with a $\mathrm{N}_{50}$ length of $553 \mathrm{bp}$. With an additional 45 plants from the focal Puflatsch population, 32 plants from other populations and 16 Gymnadenia densiflora plants we prepared multiplexed libraries for RNA 3' expression profiling by low-coverage mRNA-seq (Illumina HiSeq 2500), resulting in 166 million reads that were then mapped to the reference transcriptome. We next performed differential expression analysis between all three morphs and found 13 transcripts with significantly different expression levels. 
a
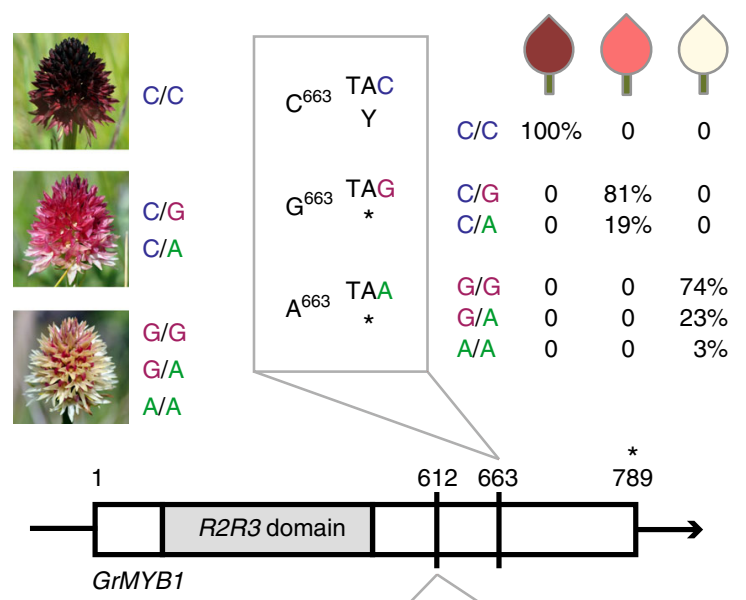

C
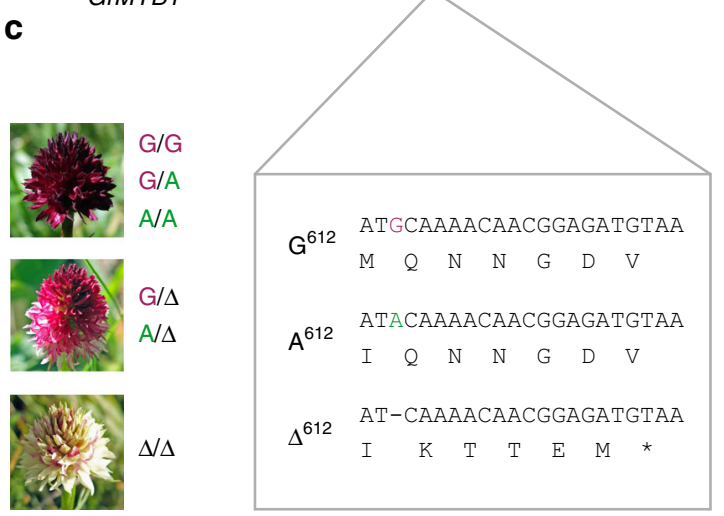

b

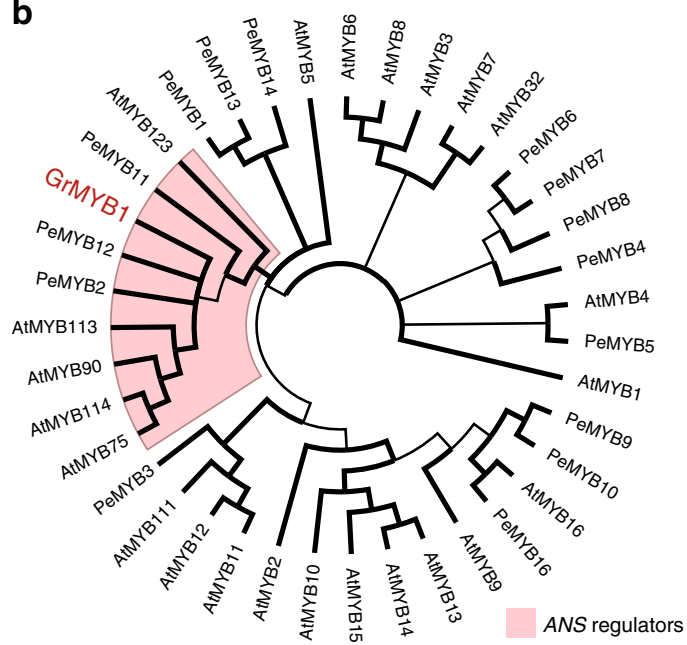

d

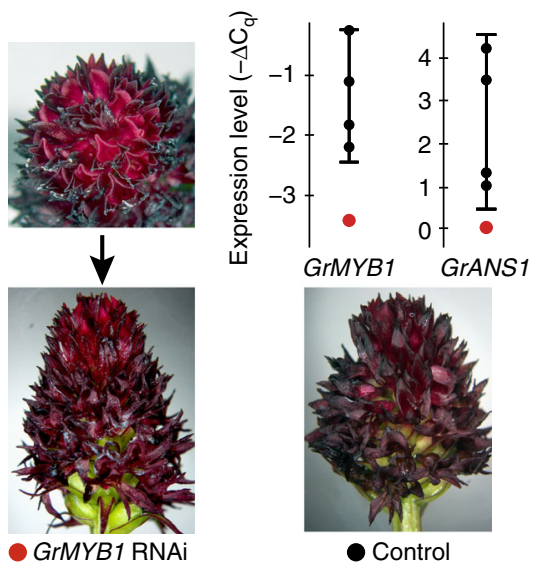

e

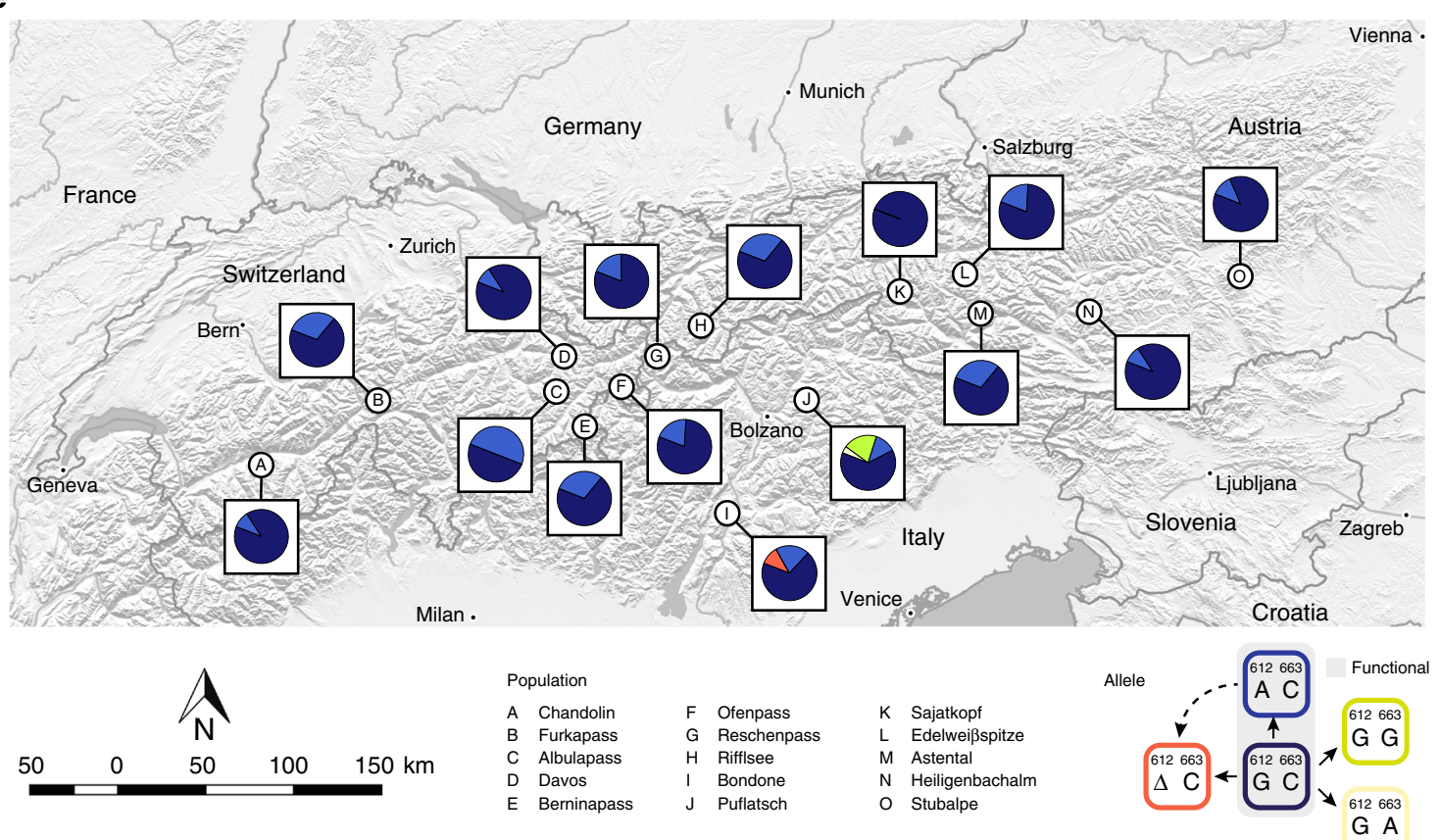

Two of these, including the one with the highest statistical support, appeared to be derived from the same anthocyanidin synthase (GrANS1) gene. ANS encodes a key enzyme in the anthocyanin pathway (Fig. 2a, c, Supplementary Fig. 5, Supplementary Table 7).
Genetic mechanism underlying the colour polymorphism. A closer inspection of the white colour morph shows that the lateral lobes of the labellum still contain anthocyanin pigment (Fig. 2d), suggesting a mutation in an associated regulatory element rather than in the GrANS1 gene itself. To find the underlying mutation, 
Fig. 3 Genetic evidence for overdominance in Gymnadenia rhellicani. a Polymorphism at Puflatsch; red morph always heterozygous for functional variant (both alternative variants truncate the protein). b Phylogenetic analysis of R2R3-MYB domains (Arabidopsis, AtMYB; Phalaenopsis, PeMYB) places GrMYB1 within ANS regulators (bold branches, posterior probability $>80 \%$ ). c Polymorphism at Bondone; derived variant (deletion/frameshift) is always

heterozygous in red and homozygous in white morph. d RNAi of GrMYB1: partial pigment loss and reduced GrMYB1 and GrANS1 expression (red; controls black, 99\% confidence intervals) in developing flowers. e Evolutionary relationships and relative frequencies of GrMYB1 alleles (linked SNP positions $612+$ 663) across the Alps; non-functional alleles at Puflatsch and Bondone. Map based on ALOS World 3D $30 \mathrm{~m}$ digital surface model from Japan Aerospace Exploration Agency, (CJAXA and administrative boundaries from GADM

we identified SNPs from the expression profiling data and performed a transcriptome-wide association study (TWAS). Here, spectral reflectance at $517 \mathrm{~nm}$ wavelength was used as the phenotype, since this is the mean of the two main cyanidins' absorption maxima (516 and $518 \mathrm{~nm}$ ). While we did not find any associations in GrANS1 itself (eight SNPs; $P=1$ for all), three of the top ten SNP associations mapped to the $3^{\prime}$ non-coding region of the same GrMYB1 gene, a member of the R2R3-MYB transcription factor family involved in the regulation of anthocyanin production (Fig. 2a, e, Supplementary Table 8). Since the expression profiles cover only the $3^{\prime}$-end of transcripts, these SNPs may not be causative themselves, but indicate the presence of alleles segregating according to colour morph. Closer inspection of the full GrMYB1 transcript revealed a non-synonymous SNP with three allelic states: C (ancestral 'wild-type'), G and A in the last exon of the coding region (Fig. 3a). Genotyping of all plants showed that black plants with high cyanidin content and GrANS1 expression are always homozygous for the wild-type allele $(\mathrm{C} / \mathrm{C})$, white plants with low cyanidin content and GrANS1 expression never contain the wild-type allele (G/G, G/A or A/A) and the red, intermediate colour morph is always heterozygous for the wild-type allele $(\mathrm{C} / \mathrm{G}$ or $\mathrm{C} / \mathrm{A})$. Both transversions $(\mathrm{C} \rightarrow \mathrm{G}$ and $\mathrm{C} \rightarrow \mathrm{A}$ ) introduce a premature stop codon, consistent with a loss of function of the derived alleles via truncating the protein by 43 amino acids. The observed segregation pattern is thus fully consistent with overdominance.

In several cases, follow-up studies on putative overdominant systems have shown that heterozygosity is not favoured due to a direct fitness effect of the identified locus, but rather due to its linkage to other loci under selection (associative overdominance) 48. Although direct functional verification of an interaction of GrMYB1 with the differentially expressed GrANS1 gene is currently infeasible in $G$. rhellicani, we conducted follow-up investigations, which strongly indicate a direct effect of GrMYB1 on plant colour patterning. First, we reconstructed the phylogenetic relationship of GrMYB1 to other $M Y B$ gene copies from Arabidopsis thaliana and the orchid Phalaenopsis. Our analysis places GrMYB1 within a clade consisting of $A$. thaliana $M Y B$ subgroup 6, and Phalaenopsis equestris MYB 2, 11 and 12, all of which have been shown to regulate ANS expression patterning in these plants ${ }^{49,50}$ (Fig. 3b).

Second, we applied double-stranded RNA to cut inflorescences of wild-type (C/C) G. rhellicani plants from a natural population so as to reduce GrMYB1 expression by RNA interference (RNAi). Of 22 treated plants (many of which were already at an advanced stage of flowering), one showed a weak and one a clear reduction in coloration of newly opening flowers, the expression of both GrMYB1 and GrANS1 being significantly decreased in the latter plant (Fig. 3d).

Third, we analysed the coding sequence of GrANS1 in 30 individuals from Puflatsch and identified 4 putative alleles from a combination of 9 SNPs. GrANS1 allelic state is neither associated with GrANS1 expression levels nor plant colour, indicating transacting regulation of GrANS1 (Supplementary Fig. 6c).

Fourth, we analysed the coding sequence of GrMYB1 in 98 individuals from 14 other $G$. rhellicani populations distributed across the Alps (Supplementary Table 1). Most of these populations contain wild-type black plants with very rare occurrences of uniformly pink or yellow mutants $(<0.1 \%)$, and both black and mutant plants contain only wild-type GrMYB1 alleles (Fig. 3e). However, one smaller population located ca. 75 $\mathrm{km}$ south-west of Puflatsch at Monte Bondone, Italy (Supplementary Table 1), contains ca. $20 \%$ plants with a phenotype resembling the red and $<1 \%$ plants with a phenotype resembling the white morph at Puflatsch (census 2015). Genotyping revealed that the nucleotide at an ancestral SNP position $(R=G$ or $A$, encoding Met or Ile) in the last coding exon of GrMYB1 is deleted $(\Delta)$ in alleles of all red and white plants analysed (Fig. 3c). Both the segregation pattern of this deletion (black: R/R; red: $\mathrm{R} / \Delta$; white: $\Delta / \Delta$ ) and its predicted effect on the protein (frameshift and truncation of 54 amino acids) are completely analogous to the Puflatsch population. Nevertheless, the two transversions discovered in the Puflatsch population do not occur at Bondone, and the deletion discovered at Bondone is absent at Puflatsch. This implies that GrMYB1 must have mutated independently in the two populations, leading to parallel evolution of bright flowers in G. rhellicani (Fig. 3e).

\section{Discussion}

Introduced into population genetics by T. Dobzhansky in $1951^{51}$, the concept of overdominance initially raised considerable controversy within the scientific community. Since then, interest in overdominance has waned because obtaining clear and complete evidence of overdominant selection in natural populations has been surprisingly difficult, especially at the genetic level ${ }^{3}$. In the few well-understood examples, heterozygotes usually have a fitness advantage because of deleterious effects in homozygotes, since (1) artificial breeding or pathogens select against wild-type homozygotes, and/or (2) the function of essential metabolic processes is impaired in derived homozygotes ${ }^{17}$. In contrast, overdominance appears to have evolved under different circumstances in G. rhellicani. The investigated colour polymorphism is not connected to breeding or diseases, and the mutation does not appear to have any detrimental effect in the homozygous state. Similar to the well-known example of heterozygote advantage at the major histocompatibility complex in vertebrates ${ }^{52}$, overdominance in $G$. rhellicani seems to be conditional on a single extrinsic factor (pollinator frequencies) instead of being maintained by superposition of an extrinsic with an opposing intrinsic factor.

Our study only lays the foundation for an understanding of the evolutionary and molecular processes in this system, and thus provides opportunities for further in-depth investigations: first, technical advances in ex situ propagation and genetic transformation of $G$. rhellicani may ultimately allow a direct functional verification of GrMYB1. Second, our study addresses plant-pollinator interactions from a plant's perspective, but detailed pollinator behaviour and efficiency as well as the ultimate causes for colour preferences by the pollinators remain to be assessed. Third, our investigations were confined to flowering individuals over a few seasons, while long-term variation of 
selection as well as the effect of the mutation on other G. rhellicani life stages are currently unknown. However, pleiotropic effects are not expected to occur, as GrMYB1 seems to be restricted in its expression pattern. Indeed, mutations in R2R3$M Y B$ transcription factors are frequently involved in evolutionary transitions of flower coloration, probably because of their minimal pleiotropic effects ${ }^{53}$. This is also highlighted by the independent origin of the derived GrMYB1 alleles in the two polymorphic G. rhellicani populations.

In conclusion, our study provides clear evidence of ordinary polymorphism maintained by overdominant selection. Overdominance therefore should not be discounted as an explanation for the frequent occurrence of polymorphism in natural populations.

\section{Methods \\ Study sites and sampling strategies. The main polymorphic G. rhellicani} population contains around 4500 individuals distributed mainly over two ridges running east-west on the volcanic outcrop of the Alm Puflatsch, Italy (Supplementary Table 1, detailed sample sizes are listed in Supplementary Table 2). The whole area is subject to intense browsing by cattle and horses during the summer, and lower parts of both ridges are usually mown in early autumn. To enable crosscomparisons, analyses included the same set of 48 plants distributed over both ridges whenever possible. The second polymorphic G. rhellicani population contains around 650 individuals and is situated on Monte Bondone, Italy (Supplementary Table 1). For the locations of all other wild-type populations see Supplementary Table 1 . To keep track of individual plants in all populations over multiple seasons, they were invisibly marked by burying passive integrated transponder (PIT) tags (HPT23, Biomark, USA) in $1.5 \mathrm{ml}$ centrifuge tubes close to the shoots. Re-localisation of tagged plants was done with a handheld Global Positioning System (GPS) receiver and a Biomark HPR Plus reader with a BP Plus portable antenna. All experiments were carried out with the required collection and CITES permits issued by the relevant authorities.

Spatial distribution analysis. In July 2015,14 plots were established in the Puflatsch population (Supplementary Fig. 1, Supplementary Table 1) with a dimension of $2 \times 2 \mathrm{~m}$, containing a total of $281 \mathrm{G}$. rhellicani plants (Supplementary Table 2). The plots were evenly distributed at $10 \mathrm{~m}$ intervals along the east-west axis of the entire Northern ridge, and a random azimuth of $0-5 \mathrm{~m}$ to the north or south. Within the plots, the position, height and colour of each flowering plant was recorded and all inflorescences were photographed. Spatial distribution of all $G$. rhellicani plants within all plots was modelled in $R(R$ v.3.2.4, $R$ Development Core Team 2016); randomness of the global spatial distribution pattern was assessed with a Kolmogorov-Smirnov Test, and differences in spatial distribution patterns between colour morphs were computed with a Studentised Permutation Test (999 random permutations $)^{54}$, both implemented in the $R$ package spatstat v.1.56- $0^{55}$.

\section{Morph frequency estimations. Census data from 1997, 1999 and 2011-2014} (courtesy of Richard Lorenz) are based on counts of inflorescences along east-west transects through the entire population, while data from 2015 to 2016 are based on counts of inflorescences within the 14 plots established in the population (see above). To ensure cross-comparability of estimations obtained with both methods, morph frequencies were additionally estimated along east-west transects by K.J.R. P.B. in 2015 when the plots were set up.

Fitness measurements. Number of flowers per inflorescence was inferred from the photographs of the plants within the 14 plots (see above) by hand-counting individual flowers with the aid of a custom marking script implemented in $R$. To correct for the fraction of flowers invisible on the photo, flower numbers were multiplied with a factor of 1.22 , which was determined by comparing flower numbers between photos and actual inflorescences. In September 2015, the tagged plants were re-localised with a handheld GPS receiver (Garmin, Switzerland) and a Biomark HPR Plus reader with a BP Plus portable antenna. The number of eaten plants was recorded, differences in herbivory between morphs were computed in $R$ with a $\chi^{2}$ test and the remaining infructescences were photographed. The number of capsules was inferred using the aforementioned custom $R$ script. To assess seed quality, the content of five capsules per individual were photographed under a microscope with transmitted light and $\times 20$ magnification (Carl Zeiss, Germany). Since orchid seeds have a transparent seed coat and do not contain an endosperm, seed viability can be estimated by assessing the presence of an embryo. Viability was estimated from 100 seeds per plant using the marking script. Number of capsules was multiplied by relative seed viability to produce reproductive fitness values. Resulting values $>0$ were BoxCox transformed using the $R$ package caret v.6.0-76. Relative fitness differences between morphs were then computed in $R$ applying a Tukey's honest significance (HSD) post hoc test on an Akaike information criterion optimised linear model with colour, standardised plant height and standardised flower number as fixed effects. In July 2016, the plots were revisited and differences in re-flowering between morphs were computed in $R$ with a $\chi^{2}$ test.

Pollinator exclusion. To avoid incidents with livestock at Puflatsch, this experiment was conducted in an ungrazed wild-type population on top of Ofenpass, Switzerland (Supplementary Table 1). The SNP data derived from low-coverage mRNA-seq (see below) suggests that this population shares its genetic ancestry with the colour-polymorphic population at Puflatsch (not shown). In June 2016, 40 plants in bud stage were randomly selected and PIT tagged, and 20 plants were covered with white glass fibre nets $(1 \mathrm{~mm}$ mesh size) attached to cylindrical metal frames of $25 \mathrm{~cm}$ height $\times 10 \mathrm{~cm}$ diameter. In September 2016, capsules were counted and seed quality was determined as described above. Fitness differences were computed in $R$ with a two-sided $t$ test.

Pollinator recordings. On the 11th of July 2015, insects observed on G. rhellicani inflorescences along east-west transects on both ridges were caught with nets in the morning (10:00) and after sunset (22:00), identified and checked for pollinia. During peak flowering in July 2016, ten Somikon (Pearl, Switzerland) and one Brinno TLC 200 (Brinno, Taiwan) time-lapse camera were placed in front of in situ pairs of black and red plants growing within ca. $10 \mathrm{~cm}$ distance of each other at the Puflatsch site. The plants were recorded at $1 \mathrm{~min}$ intervals during four consecutive days, with cameras shutting off automatically at night. Two people (R.T.K. and K.J. R.P.B.) independently screened all images for number and type of pollinators. In July 2017, pollinator recordings were repeated for three consecutive days: three freshly cut inflorescences (one per morph, randomly chosen) were randomly placed in ca. $5 \mathrm{~cm}$ distance of each other in buried $15 \mathrm{ml}$ tubes filled with water in front of each camera (9 Somikon and 1 Brinno). Differences in visitation of pollinator groups between morphs were calculated in $R$ with Holm-adjusted $\chi^{2}$ tests.

Flow cytometry. Ploidy analysis was based on a protocol in Gross and Schiest $1^{56}$ with minor modifications. Pollinia from three flowers per individual were ground in $200 \mu \mathrm{l}$ Otto 1 buffer $(0.1 \mathrm{M}$ citric acid monohydrate in $0.5 \%$ Triton X-100) in a $1.5 \mathrm{ml}$ reaction tube using a pestle. An internal standard solution was prepared by grinding $2 \mathrm{~cm}^{2}$ leaf tissue of Phaseolus coccineus 'Scarlett Emperor' (Sativa Rheinau AG, Switzerland) in $1 \mathrm{ml}$ Otto 1 solution, and filtering the suspension through a 30 $\mu \mathrm{m}$ CellTrics filter (Sysmex, Germany). After addition of $5 \mu$ of this standard solution, each sample was filtered through a $30 \mu \mathrm{m}$ CellTrics filter and centrifuged for $5 \mathrm{~min}$ at $380 \times g$. The supernatant was removed, and nuclei were resuspended in $40 \mu \mathrm{l}$ Otto 1 buffer. Samples were analysed on a Beckman Coulter Cell Lab Quanta flow cytometer (Beckman Coulter, USA) loaded with $160 \mu \mathrm{l}$ Otto 2 solution $(0.4 \mathrm{M}$ disodium phosphate heptahydrate with $4 \mu \mathrm{g} \mathrm{ml}^{-1} 4^{\prime}$,6-diamidine-2'-phenylindole dihydrochloride added before usage). Ploidy was determined as the ratio between the medians of the standard and sample peaks in the flow cytometric histogram. As G. rhellicani is generally diploid ${ }^{41}$, the lowest sample peak detected was assumed to represent the haploid pollinaria of diploid individuals, and the two adjacent peaks correspond to the diploid and (if present) tetraploid state.

Spectral mapping. Spectral measurements were taken with an AvaSpec spectrometer (Avantes, Netherlands) from three flowers per individual. The three spectral curves per sample were averaged between 300 and $700 \mathrm{~nm}$ wavelength, smoothed and normalised. The curves were mapped into the fly visual space using a custom $R$ script based on Troje ${ }^{44}$, and into the bee visual space using an $R$ script published by Sedeek et al..$^{57}$ with minor modifications.

Temperature measurements. Inflorescence temperature was measured in the morning between 09:00 and 10:00 (60 plants) and in the afternoon between 12:00 and 13:00 (90 plants) on a cloudless day in July 2016. Temperatures were recorded with an infrared thermometer (Model JHK-6606, Walter Werkzeuge, Austria) in two transects from east to west along the bottom and top part of the Northern ridge.

Micro-computed tomography. In July 2014, one flower from the lower part of the inflorescence was collected and stored in $1.5 \mathrm{ml} \mathrm{FAA}$ fixative (50\% ethanol, 5\% glacial acetic acid, 3.7\% formaldehyde). Flowers were infiltrated twice with a contrast solution (1\% phosphotungstic acid in FAA) and subsequently embedded in acryl pillow foam (DACRON ${ }^{\bullet} \mathrm{COMFOREL}^{\oplus}$, Invista, USA) according to Staedler et al. ${ }^{58}$. 3D flower morphology was obtained by $\mu \mathrm{CT}$, using a MicroXCT-200 imaging system (Xradia, USA) with a $90 \mathrm{kV}$ Microfocus X-ray. All samples were scanned with the following parameters: acceleration voltage, $37 \mathrm{kV}$; source current, $200 \mu \mathrm{A}$; exposure time, $1.5 \mathrm{~s}$; number of exposures, 728; camera binning, 4; objective, large field of view (magnification $=\times 0.4$ ); voxel size, $38.7475 \mu \mathrm{m} .3 \mathrm{D}$ data were exported in DICOM format. In Amira v.5.3.3 (Zuse Institute, Germany), a total of 21 geometric landmarks were positioned on each scanned flower: one at the base and tip of each petal, labellum and column, three along the left and right side of the labellum, one in the centre of the labellum and one at the tip of the spur (Supplementary Fig. 3d). Landmark positions were then compared among the three colour morphs with Procrustes ANOVA (analysis of variance) from the $R$ package geomorph v.3.0.359. 
Floral volatile analysis. Volatile organic compounds (VOC) were collected with non-destructive headspace sorption, a standard method also used in other Gymnadenia studies ${ }^{60}$. Entire inflorescences were enclosed in Toppits PET oven bags (Cofresco Frischhalteprodukte, Germany) and attached to a battery-driven pump connected to a glass tube loaded with $20 \mathrm{mg}$ Tenax TA (60/80 mesh, Supelco, USA). Air was pulled from the bag through the Tenax filter at a flow rate of $100 \mathrm{ml}$ $\mathrm{min}^{-1}$ for $40 \mathrm{~min}$. Background VOC levels were determined with simultaneous samples from empty oven bags. Analysis of VOC samples was done using GC-MSD as described in Gervasi and Schiest ${ }^{61}$. Identification and quantification of compounds was performed with the MSD ChemStation program E. 02.02 (Agilent, USA) based on a mass spectral library built on calibration curves using three to five different concentrations of authentic reference standards. To assess possible temporal fluctuations in intensity and composition of the scent bouquet, VOCs of 14 additional plants on the Southern ridge were collected at three different time points $(10: 00,15: 30$ and 21:00) in July 2015 and analysed as described above. Emission of the 15 compounds contributing $>0.1 \%$ to the floral bouquet was converted to $\mathrm{pgl}^{-1}$ air and BoxCox transformed to approach normality using the $R$ package caret v.6.0-7362. Differences in VOC emission between colour morphs were compared with (1) principal component analysis, and (2) Holm-adjusted linear mixed-effects models with sampling year as random factors and Tukey's HSD post hoc tests $(R$ packages nlme v.3.1-131 ${ }^{63}$ and multcomp v.1.4-6 $6^{64}$ ).

UHPLC-MS/MS of anthocyanins. In July 2014, four flowers per plant were collected from the top, centre and bottom part of the inflorescence, respectively. Flowers were flash frozen in liquid nitrogen and ground to powder using a tissue lyser (Retsch Technology, Germany). Fifty percent of each sample were weighed, transferred to a $2 \mathrm{ml}$ tube and flavonoids were extracted in $500 \mu \mathrm{l}$ of $80 \%$ methanol $(\mathrm{MeOH})$. Samples were ground again in solution, incubated overnight at $4{ }^{\circ} \mathrm{C}$ and centrifuged at $11,000 \times g$ and $4{ }^{\circ} \mathrm{C}$ for $10 \mathrm{~min}$. Supernatants were transferred to 1.5 $\mathrm{ml}$ tubes, evaporated in a Savant SpeedVac concentrator (Thermo Fisher Scientific, USA) at $42{ }^{\circ} \mathrm{C}$ and resuspended in $100 \mu \mathrm{l} 50 \% \mathrm{MeOH}+0.1 \%$ formic acid. After sonication for $5 \mathrm{~min}$, samples were centrifuged at $11,000 \times g$ and $4^{\circ} \mathrm{C}$ for $5 \mathrm{~min}$, and transferred to liquid chromatography vials. Samples were run on a UHPLC (Dionex UltiMate 3000, Thermo Fisher Scientific, USA) coupled to a Bruker compact electrospray ionisation-quadrupole-time-of-flight tandem-mass spectrometer (Bruker Daltonics, USA). The UHPLC separation was performed with a $\mathrm{C} 18$ reverse-phase column (ACQUITY UPLC TM BEH C18, $1.7 \mu \mathrm{m}, 2.1 \times 150 \mathrm{~mm}$, Waters, USA) at $28^{\circ} \mathrm{C}$ using the following gradient of solvent $\mathrm{B}$ (acetonitrile with $0.1 \%(\mathrm{v} / \mathrm{v})$ formic acid) and solvent A (water with $0.1 \%(\mathrm{v} / \mathrm{v})$ formic acid): $0-0.5$ $\min , 5 \% \mathrm{~B} ; 0.5-12 \mathrm{~min}, 5-100 \% \mathrm{~B} ; 12-14 \mathrm{~min}, 100 \% \mathrm{~B} ; 14-16 \mathrm{~min}, 100-5 \% \mathrm{~B}$. The flow rate was set up to $0.3 \mathrm{ml} \mathrm{min}^{-1}$ and $5 \mu \mathrm{l}$ of each sample was injected. The ESI source was operated in positive mode and parameters were set as follows: gas temperature, $220^{\circ} \mathrm{C}$; drying gas, $91 \mathrm{~min}^{-1}$; nebuliser, 2.2 bar; capillary voltage, $4500 \mathrm{~V}$; end plate offset, $500 \mathrm{~V}$. The instrument was set to acquire an $\mathrm{m} / z$ range of 50-1300. Conditions for MS/MS were set as described by Christ et al ${ }^{65}$. All data were recalibrated internally using pre-run injection of $10 \mathrm{mM}$ sodium hydroxide in $0.2 \%$ formic acid, $49.8 \%$ water, $50 \%$ isopropanol (v/v/v). Data Analysis v. 4.2 (Bruker Daltonics, USA) and TargetAnalysis v.1.3 (Bruker Daltonics, USA) were used to analyse the data. Absolute flavonoid quantification was based on standard curves and this analysis was performed using QuantAnalysis v.2.2 (Bruker Daltonics, USA). Flavonoids were identified and annotated by comparison with authentic reference standards data, specifically: $\mathrm{m} / z$ and MS/MS data, ultraviolet spectrum and retention time profiling except for cyanidin-3-(6-malonylglucoside), for which no reference standard was available. This compound was tentatively identified by an interpretation of the data spectrum obtained and based on previous results $^{66}$. The identified peaks were integrated and standardised by flower tissue weight and the molecular weight of the compound. Concentrations of the two main compounds cyanidin-3-glucoside and cyanidin-3-(6-malonylglucoside) were calculated based on a calibration curve of cyanidin-3-glucoside. For comparison between morphs, standardised quantities were BoxCox transformed and assessed compound-wise with Holm-adjusted ANOVA and Tukey's HSD post hoc tests using the $R$ package caret v. $6.0-76^{62}$

HPLC of carotenoids. Carotenoids were re-extracted from the anthocyanin samples (see above). Eighty microlitres of hexane were added to each sample and the solution was vortexed and incubated on ice for $10 \mathrm{~min}$. After centrifugation for 2 min at $11,000 \times g$, the upper phase was removed with a glass syringe and transferred to an amber glass vial (Supelco, USA). Samples were evaporated in a Savant SpeedVac concentrator (Thermo Fisher Scientific, USA) and resuspended in $100 \mu \mathrm{l}$ diethyl ether. As described by LaFountain et al. ${ }^{67}$, the samples were subjected to saponification prior to analysis: $100 \mu \mathrm{l}$ of $5 \%$ ethanolic $\mathrm{KOH}$ was added, and the samples were vortexed and incubated for $2 \mathrm{~h}$ in the dark at $21^{\circ} \mathrm{C}$. After addition of $400 \mu$ l hexane:diethyl ether (1:1), samples were washed with $500 \mu \mathrm{l} \mathrm{H}_{2} \mathrm{O}$ and placed on ice for phase separation. Washing of samples was repeated ca. 4-5 times until the $\mathrm{pH}$ of the aqueous phase appeared neutral on $\mathrm{pH}$ indicator paper. The upper phase was transferred to a vitreous UHPLC vial (Infochroma, Switzerland) and evaporated in a SpeedVac concentrator. Samples were re-solubilised in $60 \mu \mathrm{l}$ acetonitrile: $\mathrm{MeOH}: \mathrm{H}_{2} \mathrm{O}$ (87:10:3) and analysed on a C18 Hypersil ODS column $\left(250 \times 4.6 \mathrm{~mm}\right.$; Thermo Fisher Scientific, USA) at $25^{\circ} \mathrm{C}$ using the following gradient of solvent A (20\% $1 \mathrm{M}$ ammonium acetate, $80 \% \mathrm{MeOH})$ and B (20\% acetone,
$80 \% \mathrm{MeOH}$ ): $0-15$ min, $0-100 \%$ B; $15-25$ min, $100 \%$ B; $25-28$ min, $100-0 \%$ B; 28-32 $\mathrm{min}, 0 \% \mathrm{~B}$. The flow rate was set up to $1 \mathrm{ml} \mathrm{min}^{-1}$ and $40 \mu \mathrm{l}$ of each sample was injected. Parameters were controlled by a Gynkotek liquid chromatography system (Thermo Fisher Scientific, USA) equipped with a UVD340S diode array detector set at $450 \mathrm{~nm}$ for carotenoid identification. The two main carotenoids $\beta$ carotene and lutein were identified and quantified as described for the anthocyanins using calibration curves of authentic reference standards.

Transcriptome assembly. mRNA-seq was performed for one individual per morph from Puflatsch, one individual from Ofenpass, Switzerland, two individuals from Chandolin, Switzerland, one G. densiflora plant from each of two populations near Tschierv, Switzerland and Davos Dorf, Switzerland, one G. odoratissima plant from a population in the Münstertal, Switzerland and one G. conopsea plant from a population near Cinuos-chel-Brail, Switzerland (the latter two courtesy Karin Gross). RNA was extracted from the remaining $50 \%$ of the ground flowers used for UHPLC-MS/MS (see above). Total RNA was extracted with TRIzol reagent (Thermo Fisher Scientific, Massachusetts) according to the manufacturer's protocol and subsequently purified using a Qiagen RNeasy MinElute Cleanup Kit (Qiagen, Netherlands). RNA was quantified on a 2100 Bioanalyzer (Agilent Technologies, USA) and paired-end sequenced on one lane of an Illumina HiSeq 2500 sequencer (Illumina, USA). mRNA-seq reads were trimmed using Trimmomatic v. $0.36^{68}$ to remove Illumina adapters, leading and trailing bases below quality 3 , to truncate reads when average quality in a 4-bp sliding window dropped below 15 and finally to discard reads below $36 \mathrm{bp}$ in length. Surviving reads were then de novo assembled to transcripts using Trinity v.2.0.6

Generation of mRNA expression profiles. Expression profiling was conducted for 45 plants from Puflatsch, for 26 plants from Chandolin and for 6 plants from Ofenpass (see Supplementary Table 1 for population locations). Total RNA was extracted from the other half of the ground flower tissue used for UHPLC-MS/MS (see above) using TRIzol according to the manufacturer's protocol. Samples were quantified with a Qubit fluorometer and RNA HS Assay Kit (Thermo Fisher Scientific, USA), and libraries were prepared with a Lexogen QuantSeq 3' mRNA-Seq Kit (Lexogen, Austria) according to the manufacturer's protocol. All libraries were pooled and sequenced single-end on one lane of an Illumina HiSeq 2500 sequencer.

Differential expression analysis. Raw expression profile reads were trimmed to a minimal length of $25 \mathrm{bp}$ with Trimmomatic v. $0.36^{68}$. Trimmed reads were then mapped to the reference transcriptome, and expression levels were estimated using $R S E M$ v.1.2.31 $1^{70}$ and bowtie 2 v.2.2.9 $9^{71}$ as aligner. Posterior mean counts per morph were subsequently extracted with a custom Perl script. Transcripts with fewer than 0.5 counts per million reads in at least 10 samples were removed, and negative binomial generalised log-linear models were fitted for transcripts with at least a two-fold expression difference using edgeR v.3.12.172. Transcripts with a significant expression difference were searched against the NCBI nucleotide database (nr) with blastn ${ }^{73}$.

Transcriptome-wide association study. Trimmed expression profile reads (see above) were mapped to the indexed reference transcriptome with bowtie2 v.2.2.9 and converted to indexed bam files. Variant calling of these files was performed with samtools v.1.3 $3^{74}$ excluding bases with a quality of $<13$. The output was indexed and converted to vcf format using bcftools v.1.374. Subsequently, conversion from vcf to hapmap format was performed in $R$ v.3.2.4 using the $b i O P 4 R$ library function bdVcf2Hapmap (https://sourceforge.net/projects/biop) under exclusion of variants with a minimal depth of $<15$. Normalised spectral reflectance at $517 \mathrm{~nm}$ wavelength was extracted for each sample from the measured spectral curves (see above), and transcriptome-wide association of variants with the spectral data was assessed by fitting compressed mixed linear models with GAPIT v. $2^{75}$, including the first seven principal components. Sequences of the ten transcripts with the strongest association were searched against the NCBI nucleotide database (nr) with blastn ${ }^{73}$.

Phylogenetic analysis. Coding sequences of Arabidopsis thaliana MYB1-16, 32, $75,90,111,113,114$ and 123 and Phalaenopsis equestris MYB1-14 and MYB1-16 were retrieved from GenBank and aligned at protein level with GrMYB1 using $M E G A$ v. $7^{76}$. The sequence of the conserved R2R3 domain was extracted and used for phylogenetic analysis with MrBayes v.3.2.6 as described by Streisfeld and Rausher ${ }^{77}$. In brief, the run was performed with default settings for priors until apparent stationary of log likelihood was reached (two million generations with a sample frequency of 500, and a diagnosis frequency of 5000).

GrMYB1 genotyping. Genotyping of GrMYB1 was conducted for three sites in Italy: 88 plants from Puflatsch, 23 plants from Monte Bondone, 16 plants from Reschenpass; five sites in Switzerland: five plants each of populations from Chandolin, Furkapass, Berninapass, Davos and Ofenpass; and four sites in Austria: Rifflsee, Astental and Heiligenbachalm, and four plants from Stubalpe (Supplementary Tables 1 and 2). Total RNA was extracted with TRIzol reagent as described above, and $1 \mu \mathrm{g}$ of RNA was treated with DNAse I (Thermo Fisher 
Scientific, USA) according to the manufacturer's protocol, and then converted to complementary DNA (cDNA) using Revert-aid $\mathrm{H}^{-}$Reverse Transcriptase (Thermo Fisher Scientific, USA) according to the manufacturer's protocol. The GrMYB1 coding sequence was amplified with Phusion HotStart II polymerase (Thermo Fisher Scientific, USA); PCR: $4 \mu \mathrm{l}$ HF buffer (5x), $0.4 \mu \mathrm{l}$ dNTPs $(10 \mathrm{mM}$ each), $2 \mu \mathrm{l} \mathrm{GrMYB1-F/F2} \mathrm{primer} \mathrm{(5} \mu$ M, Supplementary Table 9), $2 \mu \mathrm{l}$ GrMYB1-R primer $(5 \mu \mathrm{M}$, Supplementary Table 9$), 0.2 \mu$ l polymerase, $1 \mu \mathrm{l}$ cDNA, $10.4 \mu \mathrm{l}$ dd $_{2} \mathrm{O}$; PCR conditions: $98^{\circ} \mathrm{C}$ for $30 \mathrm{~s}, 35$ cycles of $98^{\circ} \mathrm{C}$ for $10 \mathrm{~s}, 62.6^{\circ} \mathrm{C}$ for $30 \mathrm{~s}$, $72{ }^{\circ} \mathrm{C}$ for $30 \mathrm{~s}$, followed by $72^{\circ} \mathrm{C}$ for $5 \mathrm{~min}$. For cleanup, $5 \mu \mathrm{l}$ of PCR reaction were mixed with $0.5 \mu$ l of Exo I $\left(20 \mathrm{U} \mu \mathrm{l}^{-1}\right)$ and $2 \mu$ FastAP $\left(1 \mathrm{U} \mu \mathrm{l}^{-1}\right.$, both Thermo Fisher Scientific, Massachusetts), and incubated at $37^{\circ} \mathrm{C}$ for $20 \mathrm{~min}$ followed by inactivation at $85^{\circ} \mathrm{C}$ for $15 \mathrm{~min}$. Clean PCR reactions were Sanger sequenced on an Applied Biosystems 3130xl genetic analyser using BigDye ${ }^{\mathrm{mt}}$ Terminator v3.1 Cycle Sequencing chemistry (Thermo Fisher Scientific, USA). Sequencing PCR (10 $\mu$ l) used $2 \mu \mathrm{l}$ sequencing buffer $(5 \times), 1 \mu \mathrm{l} \mathrm{GrMYB1-F/F2/R} \mathrm{primer}(5 \mu \mathrm{M}$, Supple-

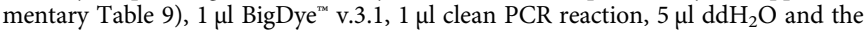
following PCR conditions: $96^{\circ} \mathrm{C}$ for $2 \mathrm{~min}, 30$ cycles of $96^{\circ} \mathrm{C}$ for $10 \mathrm{~s}, 50^{\circ} \mathrm{C}$ for $5 \mathrm{~s}$, $60^{\circ} \mathrm{C}$ for $4 \mathrm{~min}$. For plants with no or degraded RNA available, DNA was extracted from leaf tissue dried in silica gel using a Qiagen DNEasy Plant Mini Kit (Qiagen, Netherlands) according to the manufacturer's protocol, and a $385 \mathrm{bp}$ fragment in the last coding exon was amplified and sequenced as described above. Relative peak heights (fluorescence intensities) of each potential nucleotide (A, T, C, G) at the SNP positions were extracted from the.abl trace files using a custom $R$ script based upon the biOP4R library (https://sourceforge.net/projects/biop) functions bdAbifReadFile, bdAbifGetPeakLoc and bdAbifGetTrace. Nucleotides with a relative fluorescence intensity of $\geq 20 \%$ were counted as present, and the genotype of a plant was recorded as the combination of nucleotides present.

GrANS1 genotyping. Genotyping of GrANS1 was conducted for 30 plants from Puflatsch with data on GrMYB1 genotype, GrANS1 expression and sufficient cDNA left for PCR amplification. The GrANS1 coding sequence was amplified in two parts (517 and $599 \mathrm{bp}$ ) using internal primers; PCR set-up: $4 \mu \mathrm{l}$ HF buffer ( $5 \times$ ), 0.4 $\mu \mathrm{l}$ dNTPs (10 mM each), $2 \mu \mathrm{l} \mathrm{GrANS1-F/Fi} \mathrm{primer} \mathrm{(} 5 \mu \mathrm{M}$, Supplementary Table 9), $2 \mu \mathrm{l} \mathrm{GrANS1-Ri/R}$ primer $(5 \mu \mathrm{M}$, Supplementary Table 9$), 0.2 \mu \mathrm{l}$ polymerase, $1 \mu \mathrm{l}$

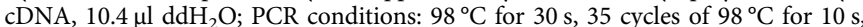
$\mathrm{T}_{\mathrm{A}}[\mathrm{F}-\mathrm{Ri}]=65.3^{\circ} \mathrm{C} / \mathrm{T}_{\mathrm{A}}[\mathrm{Fi}-\mathrm{R}]=66.1^{\circ} \mathrm{C}$ for $30 \mathrm{~s}, 72^{\circ} \mathrm{C}$ for $30 \mathrm{~s}$, followed by $72{ }^{\circ} \mathrm{C}$ for 5 min. PCR reactions were diluted 1:4 in $\mathrm{ddH}_{2} \mathrm{O}$ and Sanger sequenced using primers GrANS1-Ri/Fi at the DNA Sequencing Facility, Department of Biochemistry, University of Cambridge. Nine SNP positions were identified from these sequences and the G. rhellicani reference transcriptome (positions 67, 258, 593, $810,998,1008,1023,1029$ and 1073 in the coding sequence). Genotyping was conducted as described above.

Production of GrMYB1 dsRNA. The coding sequence of the last exon of the wildtype GrMYB1 allele was amplified with Phusion HotStart II polymerase (Thermo Fisher Scientific, USA); PCR: $4 \mu \mathrm{l} \mathrm{HF}$ buffer (5x), $0.4 \mu \mathrm{l}$ dNTPs (10 mM each), $2 \mu \mathrm{l}$ GrMYB1-attB-F primer ( $5 \mu \mathrm{M}$, Supplementary Table 9), $2 \mu \mathrm{l}$ GrMYB1-attB-R primer $(5 \mu \mathrm{M}$, Supplementary Table 9$), 0.2 \mu \mathrm{l}$ polymerase, $1 \mu \mathrm{l} \mathrm{cDNA}, 10.4 \mu \mathrm{l}$ $\mathrm{ddH}_{2} \mathrm{O}$; PCR conditions: $98^{\circ} \mathrm{C}$ for $30 \mathrm{~s}, 5$ cycles of $98^{\circ} \mathrm{C}$ for $10 \mathrm{~s}, 65^{\circ} \mathrm{C}$ for $30 \mathrm{~s}, 72^{\circ}$ C for $40 \mathrm{~s}, 35$ cycles of $98^{\circ} \mathrm{C}$ for $10 \mathrm{~s}, 72^{\circ} \mathrm{C}$ for $40 \mathrm{~s}$, followed by $72^{\circ} \mathrm{C}$ for $5 \mathrm{~min}$. PCR reactions were cleaned up with a NucleoSpin ${ }^{\circledR}$ Extract II Kit (Macherey-Nagel, Germany) according to the manufacturer's protocol. The amplicons were cloned into a pDONR207 vector via GATEWAY ${ }^{\mathrm{m}}$ cloning (Thermo Fisher Scientific, USA): $75 \mathrm{ng}$ of cleaned PCR fragment was combined with $75 \mathrm{ng}$ pDONR207 and 1 $\mu \mathrm{l}$ BP clonase II, and $\mathrm{ddH}_{2} \mathrm{O}$ was added to a total of $5 \mu$. Reactions were incubated at $25^{\circ} \mathrm{C}$ for $2 \mathrm{~h}, 0.5 \mu \mathrm{l}$ proteinase $\mathrm{K}\left(2 \mu \mathrm{g} \mu \mathrm{l}^{-1}\right)$ was added, and reactions were incubated at $37^{\circ} \mathrm{C}$ for $10 \mathrm{~min}$. Chemo-competent Escherichia coli DH5a (Thermo Fisher Scientific, USA) were transformed with this construct using a standard protocol, and plasmids were extracted with a QIAprep ${ }^{\circ}$ Spin Miniprep Kit (Qiagen, Netherlands) according to the manufacturer's protocol. In a second step, the GrMYB1 fragment was cloned into a pL4440 vector, a gift of Andrew Fire (plasmid $\# 1654$, Addgene, USA). To do so, 50 ng of pDONR207 construct were combined with $75 \mathrm{ng}$ pL4440, $1 \mu \mathrm{l}$ LR clonase II and $\mathrm{ddH}_{2} \mathrm{O}$ was added to $5 \mu$ l. The reaction was incubated as described above, and chemo-competent E. coli HT115 (courtesy of Anita Dirks) were transformed with this construct using a standard protocol. Double-strand RNA (dsRNA) was produced according to Lau et al. ${ }^{78}$ with some modifications: after overnight incubation at $37^{\circ} \mathrm{C} / 220 \mathrm{rpm}$ in $5 \mathrm{ml}$ lysogeny broth medium with $50 \mu \mathrm{g} \mathrm{ml}^{-1}$ ampicillin and $10 \mu \mathrm{g} \mathrm{ml}^{-1}$ tetracycline, the culture was diluted 1:100 in $500 \mathrm{ml} 2 \times$ yeast tryptone medium with the same concentration of antibiotics, and incubated at $37^{\circ} \mathrm{C} / 220 \mathrm{rpm}$. At $\mathrm{OD}_{600}=0.7,2 \mathrm{ml}$ of $0.1 \mathrm{M}$ isopropyl- $\beta$-D-thiogalactopyranoside was added to a final dilution of $0.4 \mathrm{mM}$, and the culture was incubated for another $2 \mathrm{~h}$ at $37^{\circ} \mathrm{C} / 220 \mathrm{rpm}$. After centrifugation for 10 $\mathrm{min}$ at $3200 \times g$, the supernatant was removed, and the pellet was resuspended in $10 \mathrm{ml}$ of $0.1 \mathrm{M}$ phosphate buffer ( $\mathrm{pH} 7.2 ; 720 \mu \mathrm{l}$ of $1 \mathrm{M} \mathrm{Na}_{2} \mathrm{HPO}_{4}, 280 \mu \mathrm{l}$ of $1 \mathrm{M}$ $\mathrm{NaH}_{2} \mathrm{PO}_{4}, 9 \mathrm{ml} \mathrm{H} \mathrm{O}$ ). Cells were disrupted in a Potter-Elvehjem homogenisator, and by freeze thawing the suspension five times with liquid nitrogen. After centrifugation for $20 \mathrm{~min}$ at $3200 \times \mathrm{g}$, the supernatant was collected, filtered through Miracloth (Merck, Germany) and stored at $-80^{\circ} \mathrm{C}$ for use in the RNAi experiment.
RNA interference. Whole, expanding G. rhellicani inflorescences were cut at Ofenpass (Supplementary Table 1) on 17 July 2017 and transferred to the lab in water-filled vases. The dsRNA solution was mixed with carborundum (400 mesh, Sigma Aldrich, Switzerland) in a Petri dish, and 22 inflorescences were inoculated by rubbing one side of the inflorescences in the solution, leaving the other side of the inflorescence untreated. Four additional inflorescences were mock inoculated the same way using $0.1 \mathrm{M}$ phosphate buffer instead of dsRNA solution. Inflorescences were kept at $21^{\circ} \mathrm{C} / 60 \%$ relative humidity $/ 150 \mu \mathrm{mol} \mathrm{m}{ }^{-2} \mathrm{~S}^{-1}$ light intensity at day (08:00 to $20: 00)$ and $12{ }^{\circ} \mathrm{C} / 60 \%$ relative humidity/dark at night. After 7 days, five flowers each from two dsRNA-treated plants showing a phenotype and the four control plants were collected in liquid nitrogen. Total RNA was extracted from these flowers, and $1 \mu \mathrm{g}$ of RNA was treated with DNAse I as described above. DNAse I-treated RNA was converted to cDNA using the double volume of reagents as described above and split into two aliquots with and without the addition of reverse transcriptase. Reverse-transcription quantitative real-time PCR (RT-qPCR) was performed in triplicates on a CFX96 Touch ${ }^{\text {tw }}$ Real-Time PCR Detection System (BioRad Laboratories, USA) using Maxima SYBR green (Thermo Fisher Scientific, USA). The PCR was set up as follows: $1.2 \mu$ forward primer (5 $\mu \mathrm{M}$, Supplementary Table 9), $1.2 \mu \mathrm{l}$ reverse primer ( $5 \mu \mathrm{M}$, Supplementary Table 9), $0.5 \mu \mathrm{l}$ ROX $(0.25 \mu \mathrm{M}), 10 \mu \mathrm{l}$ Maxima SYBR Green Master Mix, $1 \mu \mathrm{l}$ cDNA (con-

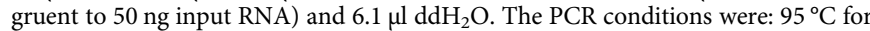
$10 \mathrm{~min}, 40$ cycles of $95^{\circ} \mathrm{C}$ for $15 \mathrm{~s}, 60^{\circ} \mathrm{C}$ for $30 \mathrm{~s}, 72^{\circ} \mathrm{C} /$ plate readout for $30 \mathrm{~s}$. The three reference genes glyceraldehyde 3-phosphate dehydrogenase (G3PDH), oligopeptidase (OPTD) and 4- $\alpha$-glucanotransferase (4- $\alpha$-GTF) have been used as control for RT-qPCR in related orchid species ${ }^{79,80}$. The reference genes were checked and showed low variation in expression between samples of our expression profiling dataset (see above). For each control and treatment plant, the quantification cycle $\left(C_{\mathrm{q}}\right)$ was averaged over all three replicates per reference gene. The average $C_{\mathrm{q}}$ of all three reference genes was then subtracted from the average $C_{\mathrm{q}}$ of each target gene to obtain $\Delta C_{\mathrm{q}}$. Ninety nine per cent confidence intervals were calculated for the $\Delta C_{\mathrm{q}}$ values of the four control plants and compared to the $\Delta C_{\mathrm{q}}$ values of each treatment plant.

Code availability. All custom scripts are available from the corresponding authors upon request.

\section{Data availability}

The generated $\mu \mathrm{CT}$ data are deposited on Phaidra under accession number 912072 , the UHPLC-MS/MS data are deposited on figshare under accession number 7321880, the mRNA-seq and Lexogen QuantSeq data are deposited on NCBI SRA under accession number PRJNA504609, the GrMYB1 allele sequences are deposited in the NCBI Genbank nucleotide database under accession numbers MK163677-MK163681, and the GrANS1 allele sequences under accession numbers MK163682-MK163685. All other datasets generated and analysed in this study are deposited on figshare under accession number 7314731. A reporting summary for this article is available as a Supplementary Information file.

Received: 14 June 2018 Accepted: 5 December 2018

Published online: 08 January 2019

\section{References}

1. Charlesworth, D. \& Willis, J. H. The genetics of inbreeding depression. Nat. Rev. Genet. 10, 783-796 (2009).

2. Dobzhansky, T. A review of some fundamental concepts and problems of population genetics. Cold Spring Harb. Symp. Quant. Biol. 20, 1-15 (1955).

3. Delph, L. F. \& Kelly, J. K. On the importance of balancing selection in plants. New Phytol. 201, 45-56 (2014).

4. Gemmell, N. J. \& Slate, J. Heterozygote advantage for fecundity. PLoS ONE 1, e125 (2006)

5. Futuyma, D. J. Evolution 2 edn (Sinauer Associates, Sunderland, 2009).

6. Aidoo, M. et al. Protective effects of the sickle cell gene against malaria morbidity and mortality. Lancet 359, 1311-1312 (2002).

7. Frelinger, J. A. The maintenance of transferrin polymorphism in pigeons. Proc. Natl. Acad. Sci. USA 69, 326-329 (1972).

8. Carrington, M. et al. HLA and HIV-1: heterozygote advantage and $B^{*} 35$ $C w^{*} 04$ disadvantage. Science 283, 1748-1752 (1999).

9. Adalsteinsson, S. Establishment of equilibrium for the dominant lethal gene for Manx taillessness in cats. Theor. Appl. Genet. 57, 49-53 (1980).

10. Karlsson, E. K. et al. Efficient mapping of Mendelian traits in dogs through genome-wide association. Nat. Genet. 39, 1321-1328 (2007).

11. Hillbertz, N. H. S. et al. Duplication of FGF3, FGF4, FGF19 and ORAOV1 causes hair ridge and predisposition to dermoid sinus in Ridgeback dogs. Nat. Genet. 39, 1318-1320 (2007).

12. Mosher, D. S. et al. A mutation in the myostatin gene increases muscle mass and enhances racing performance in heterozygote dogs. PLoS Genet. 3, e79 (2007). 
13. Fujii, J. \& Otsu, K. Identification of a mutation in porcine ryanodine receptor associated with malignant hyperthermia. Science 253, 448 (1991).

14. Greaves, J., Redfern, R., Ayres, P. \& Gill, J. Warfarin resistance: a balanced polymorphism in the Norway rat. Genet. Res. 30, 257-263 (1977).

15. Sellis, D., Kvitek, D. J., Dunn, B., Sherlock, G. \& Petrov, D. A. Heterozygote advantage is a common outcome of adaptation in Saccharomyces cerevisiae. Genetics 203, 1401-1413 (2016).

16. Gray, S. M. \& McKinnon, J. S. Linking color polymorphism maintenance and speciation. Trends Ecol. Evol. 22, 71-79 (2007).

17. Hedrick, P. W. What is the evidence for heterozygote advantage selection? Trends Ecol. Evol. 27, 698-704 (2012).

18. Svensson, E. I. Back to basics: using colour polymorphisms to study evolutionary processes. Mol. Ecol. 26, 2204-2211 (2017).

19. Kay, Q. The Role of Preferential and Assortative Pollination in the Maintenance of Flower Colour Polymorphisms Vol. 6 (Academic Press, London, 1978).

20. Russell, A. L., Newman, C. R. \& Papaj, D. R. White flowers finish last: pollenforaging bumble bees show biased learning in a floral color polymorphism. Evol. Ecol. 31, 173-191 (2017).

21. Carlson, J. E. \& Holsinger, K. E. Natural selection on inflorescence color polymorphisms in wild Protea populations: the role of pollinators, seed predators, and intertrait correlations. Am. J. Bot. 97, 934-944 (2010).

22. Irwin, R. E., Strauss, S. Y., Storz, S., Emerson, A. \& Guibert, G. The role of herbivores in the maintenance of a flower color polymorphism in wild radish. Ecology 84, 1733-1743 (2003).

23. Jersáková, J., Kindlmann, P. \& Renner, S. S. Is the colour dimorphism in Dactylorhiza sambucina maintained by differential seed viability instead of frequency-dependent selection? Folia Geobot. 41, 61-76 (2006).

24. Frey, F. M. Opposing natural selection from herbivores and pathogens may maintain floral-color variation in Claytonia virginica (Portulacaceae). Evolution 58, 2426-2437 (2004).

25. Eckhart, V. M., Rushing, N. S., Hart, G. M. \& Hansen, J. D. Frequencydependent pollinator foraging in polymorphic Clarkia xantiana ssp. xantiana populations: implications for flower colour evolution and pollinator interactions. Oikos 112, 412-421 (2006).

26. Barrett, S.C.H. (ed) Evolution and Function of Heterostyly (Springer Verlag, Berlin and Heidelberg, 2013).

27. Schemske, D. W. \& Bierzychudek, P. Spatial differentiation for flower color in the desert annual Linanthus parryae: was Wright right? Evolution 61, 2528-2543 (2007).

28. Ortiz, P., Berjano, R., Talavera, M., Rodríguez-Zayas, L. \& Arista, M. Flower colour polymorphism in Lysimachia arvensis: How is the red morph maintained in Mediterranean environments? Perspect. Plant Ecol. Evol. Syst. 17, 142-150 (2015)

29. de Jager, M. L. \& Ellis, A. G. Floral polymorphism and the fitness implications of attracting pollinating and florivorous insects. Ann. Bot. (Lond.) 113, 213-222 (2013).

30. Malerba, R. \& Nattero, J. Pollinator response to flower color polymorphism and floral display in a plant with a single-locus floral color polymorphism: consequences for plant reproduction. Ecol. Res. 27, 377-385 (2012).

31. Subramaniam, B. \& Rausher, M. D. Balancing selection on a floral polymorphism. Evolution 54, 691-695 (2000).

32. Takahashi, Y., Takakura, K.-i. \& Kawata, M. Flower color polymorphism maintained by overdominant selection in Sisyrinchium sp. J. Plant Res. 128 933-939 (2015).

33. Mojonnier, L. E. \& Rausher, M. D. Selection on a floral color polymorphism in the common morning glory (Ipomoea purpurea): the effects of overdominance in seed size. Evolution 51, 608-614 (1997).

34. Coberly, L. C. \& Rausher, M. D. Pleiotropic effects of an allele producing white flowers in Ipomoea purpurea. Evolution 62, 1076-1085 (2008).

35. Takahashi, Y., Takakura, K.-i \& Kawata, M. Spatial distribution of flower color induced by interspecific sexual interaction. PLoS ONE 11, e0164381 (2016).

36. Kral, F. Ein pollenanalytischer Beitrag zur Vegetationsgeschichte der Seiser Alm. Der Schlern 57, 31-36 (1983).

37. Torre, K. W. D., Magnus, P. W. \& von Sarthein, L. Flora der gefürsteten Grafschaft Tirol, des Landes Vorarlberg und des Fürstenthumes Liechtenstein: Bd. Die Farn- und Blütenpflanzen (Pteriodphyta et Siphonogama) 529-530 (Wagner'sche Universitäts-Buchhandlung, Innsbruck, 1906).

38. Reinhard, H. R. in Vol. Animals, Plants and Biotopes (ed Gölz, P.) (ETHBibliothek, Zurich, 1971).

39. Moen, A. \& Øien, D. I. Ecology and survival of Nigritella nigra, a threatened orchid species in Scandinavia. Nord. J. Bot. 22, 435-461 (2002).

40. Zhang, X. S. \& O'Neill, S. D. Ovary and gametophyte development are coordinately regulated by auxin and ethylene following pollination. Plant Cell 5, 403-418 (1993).

41. Hedrén, M., Klein, E. \& Teppner, H. Evolution of polyploids in the European orchid genus Nigritella: evidence from allozyme data. Phyton 40, 239-275 (2000).
42. Müller, H. Fertilisation of flowers by insects. Nature 11, 110-112 (1874)

43. Vöth, W. Gymnadenia, Nigritella und ihre Bestäuber. J. Eur. Orchid 32, 547-573 (2000)

44. Troje, N. Spectral categories in the learning behaviour of blowflies. $Z$. Naturforsch. C. 48, 96-104 (1993)

45. Lunau, K. Visual ecology of flies with particular reference to colour vision and colour preferences. J. Comp. Physiol. 200, 497 (2014).

46. Chittka, L. The colour hexagon: a chromaticity diagram based on photoreceptor excitations as a generalized representation of colour opponency. J. Comp. Physiol. A 170, 533-543 (1992).

47. Tava, A., Cecotti, R. \& Confalonieri, M. Characterization of the volatile fraction of Nigritella nigra (L.) Rchb. F. (Orchidaceae), a rare species from the central Alps. J. Essent. Oil Res. 24, 39-44 (2012).

48. Zhao, L. \& Charlesworth, B. Resolving the conflict between associative overdominance and background selection. Genetics 203, 1315-1334 (2016).

49. Hsu, C.-C., Chen, Y.-Y., Tsai, W.-C., Chen, W.-H. \& Chen, H.-H. Three R2R3-MYB transcription factors regulate distinct floral pigmentation patterning in Phalaenopsis spp. Plant Physiol. 168, 175-191 (2015).

50. Gonzalez, A., Zhao, M., Leavitt, J. M. \& Lloyd, A. M. Regulation of the anthocyanin biosynthetic pathway by the TTG1/bHLH/Myb transcriptional complex in Arabidopsis seedlings. Plant J. 53, 814-827 (2008).

51. Dobzhansky, T. Genetics and the Origin of Species (Columbia University Press, New York, 1951).

52. Doherty, P. C. \& Zinkernagel, R. M. Enhanced immunological surveillance in mice heterozygous at the $H-2$ gene complex. Nature 256, 50 (1975).

53. Streisfeld, M. A. \& Rausher, M. D. Population genetics, pleiotropy, and the preferential fixation of mutations during adaptive evolution. Evolution 65, 629-642 (2011).

54. Hahn, U. A studentized permutation test for the comparison of spatial point patterns. J. Am. Stat. Assoc. 107, 754-764 (2012).

55. Baddeley, A., Rubak, E. \& Turner, R. Spatial Point Patterns: Methodology and Applications with $R$ (Chapman \& Hall/CRC, Boca Raton, 2015).

56. Gross, K. \& Schiestl, F. P. Are tetraploids more successful? Floral signals, reproductive success and floral isolation in mixed-ploidy populations of a terrestrial orchid. Ann. Bot. (Lond.) 115, 263-273 (2015).

57. Sedeek, K. E. et al. Genic rather than genome-wide differences between sexually deceptive Ophrys orchids with different pollinators. Mol. Ecol. 23, 6192-6205 (2014).

58. Staedler, Y. M., Masson, D. \& Schönenberger, J. Plant tissues in 3D via X-ray tomography: simple contrasting methods allow high resolution imaging. PLoS ONE 8, e75295 (2013).

59. Adams, D. C. \& Otárola-Castillo, E. geomorph: an R package for the collection and analysis of geometric morphometric shape data. Methods Ecol. Evol. 4, 393-399 (2013).

60. Huber, F. K., Kaiser, R., Sauter, W. \& Schiestl, F. P. Floral scent emission and pollinator attraction in two species of Gymnadenia (Orchidaceae). Oecologia 142, 564-575 (2005).

61. Gervasi, D. D. \& Schiestl, F. P. Real-time divergent evolution in plants driven by pollinators. Nat. Commun. 8, 14691 (2017).

62. Kuhn, M. Caret: Classification and Regression Training (Astrophysics Source Code Library, 2015)

63. Pinheiro, J., Bates, D., DebRoy, S., Sarkar, D. \& Team, R. C. nlme: Linear and nonlinear mixed effects models. R. Package Version 3, 96 (2009).

64. Hothorn, T., Bretz, F. \& Westfall, P. Simultaneous inference in general parametric models. Biom. J. 50, 346-363 (2008).

65. Christ, B., Hauenstein, M. \& Hörtensteiner, S. A liquid chromatography-mass spectrometry platform for the analysis of phyllobilins, the major degradation products of chlorophyll. Plant J. 88, 505-518 (2016).

66. Schütz, K., Persike, M., Carle, R. \& Schieber, A. Characterization and quantification of anthocyanins in selected artichoke (Cynara scolymus L.) cultivars by HPLC-DAD-ESI-MSn. Anal. Bioanal. Chem. 384, 1511-1517 (2006).

67. LaFountain, A. M., Frank, H. A. \& Yuan, Y.-W. Carotenoid composition of the flowers of Mimulus lewisii and related species: implications regarding the prevalence and origin of two unique, allenic pigments. Arch. Biochem. Biophys. 573, 32-39 (2015)

68. Bolger, A. M., Lohse, M. \& Usadel, B. Trimmomatic: a flexible trimmer for Illumina sequence data. Bioinformatics 30, 2114-2120 (2014).

69. Grabherr, M. G. et al. Trinity: reconstructing a full-length transcriptome without a genome from RNA-seq data. Nat. Biotechnol. 29, 644 (2011).

70. Li, B. \& Dewey, C. N. RSEM: accurate transcript quantification from RNA-Seq data with or without a reference genome. BMC Bioinformatics 12, 323 (2011).

71. Langmead, B. \& Salzberg, S. L. Fast gapped-read alignment with Bowtie 2. Nat. Methods 9, 357-359 (2012).

72. Robinson, M. D., McCarthy, D. J. \& Smyth, G. K. edgeR: a bioconductor package for differential expression analysis of digital gene expression data. Bioinformatics 26, 139-140 (2010). 
73. Altschul, S. F., Gish, W., Miller, W., Myers, E. W. \& Lipman, D. J. Basic local alignment search tool. J. Mol. Biol. 215, 403-410 (1990).

74. Li, $\mathrm{H}$. et al. The sequence alignment/map format and SAMtools. Bioinformatics 25, 2078-2079 (2009).

75. Lipka, A. E. et al. GAPIT: genome association and prediction integrated tool. Bioinformatics 28, 2397-2399 (2012).

76. Tamura, K., Dudley, J., Nei, M. \& Kumar, S. MEGA4: molecular evolutionary genetics analysis (MEGA) software version 4.0. Mol. Biol. Evol. 24, 1596-1599 (2007).

77. Streisfeld, M. A. \& Rausher, M. D. Altered trans-regulatory control of gene expression in multiple anthocyanin genes contributes to adaptive flower color evolution in Mimulus aurantiacus. Mol. Biol. Evol. 26, 433-444 (2008).

78. Lau, S. et al. Crude extracts of bacterially-expressed dsRNA protect orchid plants against Cymbidium mosaic virus during transplantation from in vitro culture. J. Hortic. Sci. Biotechnol. 89, 569-576 (2014).

79. Monteiro, F. et al. Labellum transcriptome reveals alkene biosynthetic genes involved in orchid sexual deception and pollination-induced senescence. Funct. Integr. Genom. 12, 693-703 (2012).

80. Schlüter, P. M. et al. Stearoyl-acyl carrier protein desaturases are associated with floral isolation in sexually deceptive orchids. Proc. Natl. Acad. Sci. USA 108, 5696-5701 (2011)

\section{Acknowledgements}

This study would not have been possible without the dedicated support of Mathias Kneubühler and his trusty Land Rover. We also thank Richard Lorenz and Giorgio Perazza for sharing their population census data, Andreas Tribsch for providing additional plant samples and Anita Dirks for providing the E. coli HT115 strain. In addition, we thank Richard Lorenz, Benjamin Kellenberger, Johann Madl, Giorgio Perazza, Sebastiano Andreatta, Tobias Kellenberger, Karin Gross and Khalid Sedeek for fieldwork support, as well as Srignanakshi Iyer, Laura Piñeiro Fernández, Barbara Keller, Franz Huber, Beverley Glover, Wolf Blanckenhorn, Philip Jörg and Christoph Gasser for laboratory and technical assistance and advice. We further thank Marialuise Kiem, Amt für Landschaftsökologie Bozen, as well as the environmental authorities of Wallis, Uri, Graubünden, Carinthia, the Tyrol, Styria and Trento for issuing collection permits. This study was funded by a University of Zurich (UZH) Forschungskredit grant to R.T.K., a PLANT FELLOWS Postdoctoral Fellowship grant to K.J.R.P.B., and three travel grants from the Claraz Schenkung Zurich (two to R.T.K. and one to K.J.R.P.B.). P.M.S. acknowledges support by the Swiss National Science Foundation (SNF, project 31003A_155943).

\section{Author contributions}

R.T.K., K.J.R.P.B. and P.M.S. conceived and designed the study. R.T.K., K.J.R.P.B. and P. M.S. conducted the field investigations. R.T.K., K.J.R.P.B. and F.P.S. performed all phenotypic and scent analyses. Y.M.S., K.J.R.P.B., R.T.K. and J.S. carried out the 3D morphometric analysis. R.M.D.B.F. and R.T.K. conducted the anthocyanin analysis. A.M. LF., R.M.D.B.F. and R.T.K. carried out the carotenoid analysis. K.J.R.P.B., R.T.K. and P. M.S. performed the transcriptome assembly and analysis. R.T.K. and P.M.S. conducted the genetic analysis. R.T.K., P.M.S. and K.J.R.P.B. wrote the software used for the analysis. R.T.K. and P.M.S. wrote the original draft of the manuscript. All authors discussed and edited the manuscript. F.P.S., P.M.S. and J.S. provided resources for this study. P.M. S., R.T.K. and K.J.R.P.B. acquired funding for this project.

\section{Additional information}

Supplementary Information accompanies this paper at https://doi.org/10.1038/s41467018-07936-x.

Competing interests: The authors declare no competing interests.

Reprints and permission information is available online at http://npg.nature.com/ reprintsandpermissions/

Publisher's note: Springer Nature remains neutral with regard to jurisdictional claims in published maps and institutional affiliations.

(c) (i) Open Access This article is licensed under a Creative Commons Attribution 4.0 International License, which permits use, sharing, adaptation, distribution and reproduction in any medium or format, as long as you give appropriate credit to the original author(s) and the source, provide a link to the Creative Commons license, and indicate if changes were made. The images or other third party material in this article are included in the article's Creative Commons license, unless indicated otherwise in a credit line to the material. If material is not included in the article's Creative Commons license and your intended use is not permitted by statutory regulation or exceeds the permitted use, you will need to obtain permission directly from the copyright holder. To view a copy of this license, visit http://creativecommons.org/ licenses/by/4.0/.

(C) The Author(s) 2019 